\title{
Preparation and characterization of three- dimension porous collagen/graphene oxide/hydroxyapatite nanocomposite scaffolds for bone tissue engineering
}

\author{
Bhahat Lawlley Zimba ${ }^{1,2 *}$, Hao Jiang ${ }^{1}$, Li Chen ${ }^{1}$, Yaomin $\mathrm{Li}^{1}$, \\ Xunzhi $\mathrm{Yu}^{1}$, Chang Chen ${ }^{1}$, Jiangling Wan ${ }^{1}$, Qungzhi Wu ${ }^{1}$ \\ ${ }^{1}$ Wuhan University of Technology, Wuhan, China \\ ${ }^{2}$ Malawi University of Science and Technology, Malawi \\ *Corresponding author: Bhahat Lawlley Zimba: bahat.zimba@yahoo.com
}

\section{OPEN ACCESS}

Citation: Zimba B.L., Jiang H., Chen L., Li Y., Yu X., Chen C., Wan J., Wu Q. (2019) Preparation and characterization of three-dimension porous collagen/graphene oxide/hydroxyapatite nanocomposite scaffolds for bone tissue engineering. Open Science Journal 4(1)

Received: $11^{\text {th }}$ May 2019

Accepted: $12^{\text {th }}$ August 2019

Published: $24^{\text {th }}$ October 2019

Copyright: (C) 2019 This is an open access article under the terms of the Creative Commons Attribution License, which permits unrestricted use, distribution, and reproduction in any medium, provided the original author and source are credited.

Funding: The author(s) received no specific funding for this work

Competing Interests: The author have declared that no competing interests exists.

\section{Abstract:}

Studies have reported that the incorporation of graphene oxide (GO) and hydroxyapatite (HA) into biocompatible polymers (such as collagen (Col), chitosan, alginate, etc) results in enhanced structural and mechanical properties respectively. The objective of this study was to prepare and characterize three-dimensional (3D) porous $\mathrm{Col} / \mathrm{GO} / \mathrm{HA}$ nanocomposite scaffolds and to investigate cytocompatibility and osteogenic differentiation potential of rat bone marrow mesenchymal stem cells (rBMSCs) on the as-prepared scaffolds. The SEM images revealed that the scaffolds were porous with the pore diameter inversely proportional to the concentration of HA. XRD results were able to depict the characteristic peaks for HA which shows that HA was incorporated into the scaffolds. The rBMSCs which were cultured on the scaffolds were able to attach and proliferate during the 21 days of the experiment which indicates that the as-prepared scaffolds are cytocompatible. The Alizarin red staining demonstrated the presence of calcium deposits as there were orange-red stains on the samples after culturing the cells using the osteogenic differentiation medium. These results demonstrate the promising potential of the $3 \mathrm{D}$ porous $\mathrm{Col} / \mathrm{GO} / \mathrm{HA}$ nanocomposite scaffolds for applications in bone tissue engineering.

Keywords: Collagen, Graphene oxide, Hydroxyapatite, Porous scaffolds, Tissue engineering. 


\section{Introduction}

Scaffolds are used to restore or regenerate damaged tissue in tissue engineering by providing a framework for cells to attach, proliferate, and form extracellular matrix of the targeted tissue [1]. These scaffolds may also serve as carriers for cells, growth factors, and other bimolecular signals. For the scaffolds to effectively aid tissue restoration and regeneration, they also need to exhibit certain characteristics like being biocompatible with the biological systems of the body and they have to be able to undergo biodegradation once implanted [2]. These scaffolds are also supposed to be fabricated in such a way that they should have proper interconnected pores with proper pore size. This will require the scaffolds to have a proper three-dimensional (3D) porous structure when it is being synthesized. There is also need for the scaffolds to have an excellent surface chemistry, topography and adequate mechanical properties [3].

Freeze-drying, which is one of the most common techniques for fabricating scaffolds, was used in this study to prepare collagen (Col)/graphene oxide (GO)/hydroxyapatite ( $\mathrm{HA}$ ) nanocomposite scaffolds for bone tissue engineering. Col was selected to be used due to its great biocompatibility, degradability, and its inherent structural architecture [4]. GO was incorporated due to its distinct and extraordinary physical, chemical, and mechanical properties [5]. Studies have also shown GO-containing biomaterials to be biocompatible, non-cytotoxic, and that they allow effective adhesion and proliferation of human and mammalian cells [6]. Girao et al. [7] reported that the inclusion of GO in Col biomaterials resulted into enhanced structural properties of the materials and this depended both on the $\mathrm{pH}$ of the medium used and the weight ratio of $\mathrm{GO} / \mathrm{Col}$ used during the fabrication. Addition of GO also enhanced osteogenic differentiation of the human mesenchymal stem cells (hMSCs) that were cultured on the GO/Col as compared to those cells cultured on pure Col scaffolds [8].

On the other hand, the incorporation of $\mathrm{HA}$ which is mostly calcium phosphate $(\mathrm{CaP})$, has shown considerable increase in the mechanical properties of the biomaterials, a better cellular migration, proliferation and differentiation after stem cells were seeded on the scaffolds $[9,10]$. The presence of $\mathrm{CaP}$ in Col-based scaffolds has been reported to increase the compressive modulus of up to $1.3 \mathrm{kPa}$ as compared to that of pure Col scaffolds [11]. The compressive modulus has been said to be directly proportional to the concentration of $\mathrm{CaP}$ in the scaffolds.

Despite this demonstrated potential of GO and HA in enhancing the structural as well as functional properties of Col scaffolds, the preparation and characterisation of $\mathrm{Col} / \mathrm{GO} / \mathrm{HA}$ nanocomposite scaffolds for bone tissue engineering has not yet been thoroughly investigated. It is against this background that this study wants to investigate the preparation and characterisation of $\mathrm{Col} / \mathrm{GO} / \mathrm{HA}$ freeze-dried nanocomposite scaffolds that can have applications in bone tissue engineering. In this work, a series of $3 \mathrm{D}$ porous $\mathrm{Col} / \mathrm{GO} / \mathrm{HA}$ nanocomposite scaffolds were prepared through freeze-drying technique. The as-prepared $\mathrm{Col} / \mathrm{GO} / \mathrm{HA}$ porous scaffolds were characterized through scanning electron microscopy (SEM), X-ray diffraction (XRD), Fourier Transform Infra-Red (FT-IR) spectrum, mechanical test. Furthermore, the cytocompatibility and the osteogenesis ability of the rat bone marrow stem cells (rBMSCs) on the as-prepared scaffolds were evaluated in vitro. 


\section{Materials and Methods}

\section{Reagents}

Lyophilised collagen (acid soluble) was purchased from Sichuan Ming Yi Biotechnology Co., Ltd (China). The modified Hummers' method [12] was used to synthesize Graphene oxide. Calcium hydroxide $\left(\mathrm{Ca}(\mathrm{OH})_{2}\right)$ and Sodium tripolyphosphate $\left(\mathrm{Na}_{5} \mathrm{P}_{3} \mathrm{O}_{10}\right)$ (Sinopharm. Chemical Reagent Co., Ltd) were of analytical grade. Hydroxyapatite was prepared within the laboratory from Calcium hydroxide and Sodium tripolyphosphate by modifying the method used by Yang et. al [13]. Healthy 12 weeks old specific pathogen free grade Wistar rats were sacrificed and BMSCs were extracted from the femur and tibia. The stem cells were then sub-cultured in complete growth medium.

\section{Preparation of the $3 \mathrm{D}$ porous Col/GO/HA nanocomposite scaffolds}

An aqueous acetic acid (AA) solution was prepared by diluting $0.642 \mathrm{~mL}$ of $\mathrm{AA}$ in $85 \mathrm{~mL}$ of deionised water. Col was dissolved in the AA aqueous solution until the solution was homogenous, then $10 \mathrm{~mL}$ of GO solution $(0.001 \mathrm{mg} / \mathrm{mL})$ was added. Finally, HA was added to the solution at different concentrations. The samples were then frozen at a final freezing temperature of $-20^{\circ} \mathrm{C}$ for $24 \mathrm{hrs}$. Thereafter, the samples were lyophilized in a vacuum at $-51^{\circ} \mathrm{C}$ for $36 \mathrm{hrs}(12 \mathrm{hrs}$ per day for 3 days) to obtain the scaffolds. In between the freeze-drying, the samples were kept frozen at $-20^{\circ} \mathrm{C}$.

Six samples were prepared and the concentration of Col was kept constant ( $0.5 \%$ wt./vol.) in all the samples. Out of the six samples, GO was added to five of them at a constant concentration $(0.01 \% \mathrm{wt} . / \mathrm{vol}$.). Only four of the samples contained HA in them. The ratio of $\mathrm{HA}$ : Col in the four samples was 0.25:1, 0.5:1, 1:1 and 1.25:1, respectively. One sample only contained Col and GO and the last sample which was used as a control sample only contained Col dissolved in aqueous AA.

\section{Characterizations of the as-prepared porous scaffolds}

The microstructure of the as-prepared scaffolds was analysed using the scanning electron microscopy (SEM). The samples were cut into $0.5 \mathrm{~cm}$ by $0.3 \mathrm{~cm}$ and were fixed to an adhesive carbon stub. Then the samples were coated with gold in vacuum using an ion sputter (HITACHI E-1010) to enhance their conductivity during imaging. The microstructure of the scaffolds was imaged by a Scanning Electron Microscope (HITACHI S-4800) at a voltage of $5.0 \mathrm{kV}$ to examine the surfaces of the scaffolds and the interconnection of the pores in the scaffolds. Fourier Transform Infra-Red (FTIR) spectroscopy was used to compare and analyse the characteristics of the as-prepared scaffolds. The compressive stress of the as-prepared nanocomposite scaffolds was measured using INSTRON (ElectroPuls E1000, America). 


\section{In vitro analysis}

Cell viability was determined by seeding rat rBMSCs, that were harvested from Wistar rats, on the scaffolds in 24-well culture plates at a density of $2 \times 10^{3}$ cells/well using Dulbecco's Modified Eagle's Medium (DMEM) supplemented with $15 \%$ foetal bovine serum (FBS) and $1 \%$ penicillin/streptomycin. The cells were then incubated with $100 \mathrm{uL}$ of MTT $(0.5 \mathrm{mg} / \mathrm{mL}, 3-(4,5$-dimethyl-2thiazolyl)-2,5-diphenyl-2-H-tetrazolium bromide) at $37^{\circ} \mathrm{C}$ for $4 \mathrm{hrs}$. Thereafter, the reagent was removed and $500 \mathrm{uL}$ of DMSO was added to each well. $150 \mathrm{uL}$ of DMSO solution was transferred to 96 -well culture plate before evaluating the cell number in each well using an enzyme-linked immunosorbent assay.

Cell morphology was analysed by seeding rBMSCs on the scaffolds in 24-well culture plates at a density of $2 \times 10^{3}$ cells $/ \mathrm{cm} 2$ using growth medium. After 7 days, cells were fixed in $4 \%(\mathrm{vol} / \mathrm{vol})$ paraformaldehyde for $30 \mathrm{~min}$ at room temperature. The cells were then dehydrated gradually by using ethanol solutions with different concentrations before the scaffolds were freeze-dried. The scaffolds were coated with gold ions in vacuum before being examined. SEM was then used to observe the cell morphology on the scaffolds.

To evaluate the osteogenic differentiation abilities of the cells on the scaffolds, rBMSCs were seeded on the scaffolds at a density of $2 \times 10^{3}$ cells/well using osteogenic induction medium (DMEM supplemented with $15 \%$ FBS, $1 \%$ penicillin/streptomycin, $10 \mathrm{nM}$ dexamethasone, $10 \mathrm{mM} \quad \beta$-glycerophosphate and $0.2 \mathrm{mM}$ ascorbic acid). After 14 days, rBMSCs were then fixed with $4 \%(\mathrm{vol} / \mathrm{vol})$ paraformaldehyde for $30 \mathrm{~min}$ at room temperature. The fixed cells were then stained with Alizarin Red Solution $\left(2 \%\right.$ ) for $30 \mathrm{~min}$ at $37^{\circ} \mathrm{C}$ before being viewed under a light microscope. Alizarin red staining has been used extensively to demonstrate the osteogenic differentiation potential of various stem cells in bone regeneration studies [14-16].

\section{Results}

\section{Structural characteristics of the scaffolds}

The scaffold porosity was analysed and it was determined using the formula below:

$$
\text { Porosity }=\underline{\mathrm{Wt}-\mathrm{Wr}-\mathrm{Wd}} \times 100 \%
$$

Wc-Wr

Where, Wc is the weight of container filled with ethanol, $\mathrm{Wd}$ is the weight of the dry scaffolds only, Wt is the total weight of the container filled with ethanol and the dry scaffold that has been soaked in the container, and Wr is the weight of the container filled with ethanol after removing the soaked scaffold [17]. Using the above formula, it was found that the porosity of the scaffolds was as follows: $\mathrm{Col} / \mathrm{GO} / \mathrm{HA}(\mathrm{HA}: \mathrm{Col}=0.25: 1)$ had a porosity of $99.9 \%, \mathrm{Col} / \mathrm{GO} / \mathrm{HA}(\mathrm{HA}: \mathrm{Col}$ $=0.5: 1)$ was $99.4 \%$ porous, $\mathrm{Col} / \mathrm{GO} / \mathrm{HA}(\mathrm{HA}: \mathrm{Col}=1: 1)$ had $99.1 \%, \mathrm{Col} / \mathrm{GO} / \mathrm{HA}$ 
(HA:Col =1.25:1) had 98.3\%, $\mathrm{Col} / \mathrm{GO}$ had $99.4 \%$ and pure Col had $99.9 \%$ porosity results.

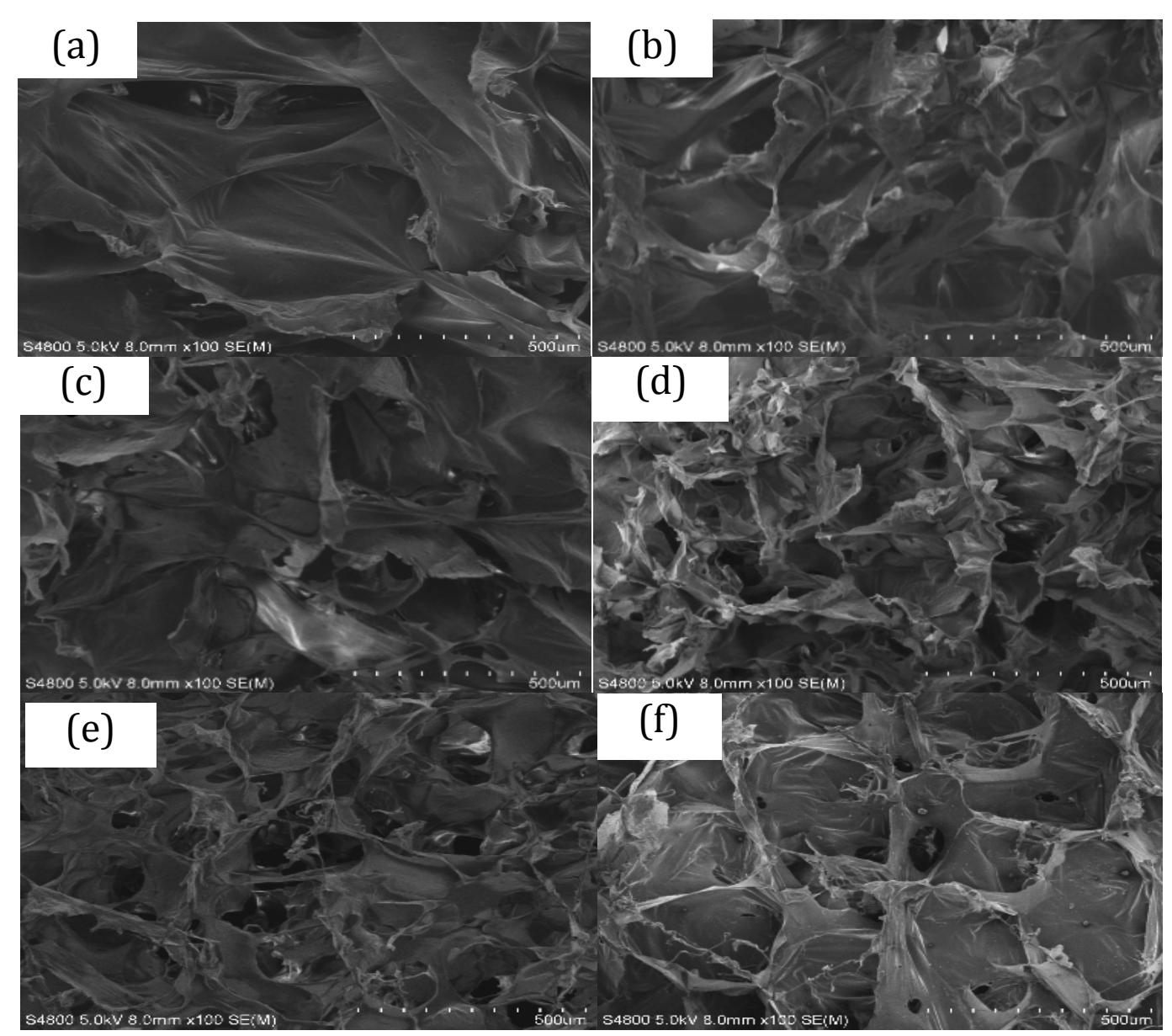

Figure 1. SEM images of as-prepared porous scaffolds. (a) Col/GO/HA (HA:Col =0.25:1); (b) $\mathrm{Col} / \mathrm{GO} / \mathrm{HA}(\mathrm{HA}: \mathrm{Col}=0.5: 1) ;(\mathrm{c}) \mathrm{Col} / \mathrm{GO} / \mathrm{HA}(\mathrm{HA}: \mathrm{Col}=1: 1) ;(\mathrm{d}) \mathrm{Col} / \mathrm{GO} / \mathrm{HA}(\mathrm{HA}: \mathrm{Col}$ $=1.25: 1)$; (e) Col/GO; and (f) pure Col.

Figure 1 above shows SEM images of as-prepared $\mathrm{Col} / \mathrm{GO} / \mathrm{HA}, \mathrm{Col} / \mathrm{GO}$ and pure Col scaffolds. The images show the scaffolds having macropores with diameter ranging between 30-350 $\mu \mathrm{m}$. The scaffolds with a higher concentration of HA have a smaller number of pores with a diameter larger than $100 \mu \mathrm{m}$. 


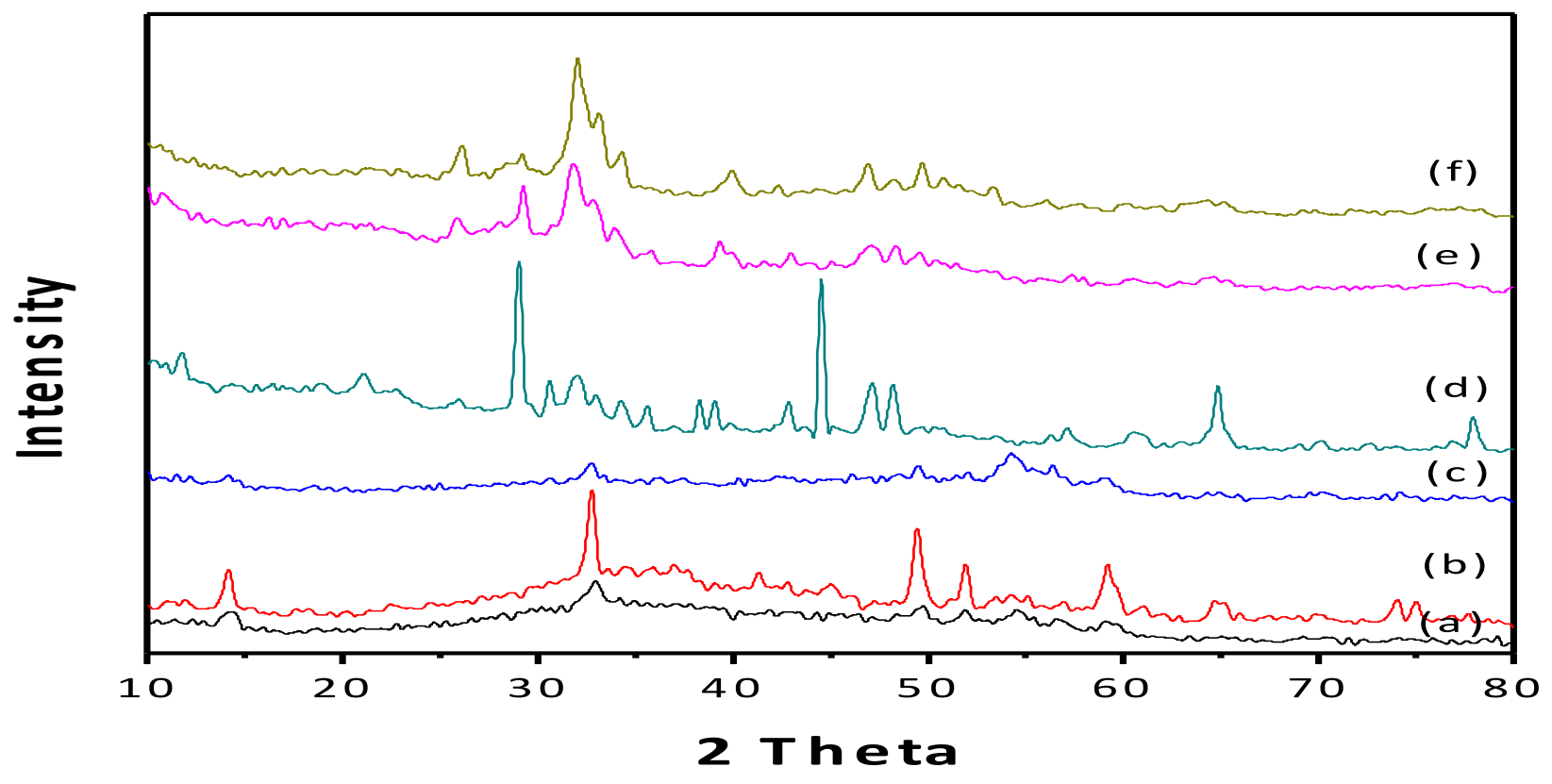

Figure 2. XRD patterns of as-prepared porous scaffolds. (a) $\mathrm{Col} / \mathrm{GO} / \mathrm{HA}(\mathrm{HA}: \mathrm{Col}=0.25: 1)$; (b) $\mathrm{Col} / \mathrm{GO} / \mathrm{HA}(\mathrm{HA}: \mathrm{Col}=0.5: 1) ;(\mathrm{c}) \mathrm{Col} / \mathrm{GO} / \mathrm{HA}(\mathrm{HA}: \mathrm{Col}=1: 1) ;(\mathrm{d}) \mathrm{Col} / \mathrm{GO} / \mathrm{HA}(\mathrm{HA}: \mathrm{Col}$ $=1.25: 1$ ); (e) $\mathrm{Col} / \mathrm{GO}$; and (f) pure Col.

The XRD machines was used to analyse the incorporation of $\mathrm{HA}$ and GO materials into the Col scaffolds. Figure 2 above shows the XRD patterns of pure $\mathrm{Col}, \mathrm{Col} / \mathrm{GO}$, and $\mathrm{Col} / \mathrm{GO} / \mathrm{HA}$ composite scaffolds. Different peaks were recorded in the $\mathrm{XRD}$ patterns and some of which are characteristic peaks for the materials which were used in this study. $\mathrm{Col} / \mathrm{GO} / \mathrm{HA}$ composite scaffolds showed the characteristic peaks for $\mathrm{HA}$ that appeared at $2 \theta=31.7^{\circ}$ (for $\mathrm{HA}$ :Col $=0.25: 1$ ), $25.8^{\circ} \& 31.7^{\circ}$ (for $\mathrm{HA}: \mathrm{Col}=0.5: 1$ ), $32.2^{\circ} \& 32.8^{\circ}$ (for $\mathrm{HA}: \mathrm{Col}=1: 1$ ), and $31.7^{\circ} \& 32.2^{\circ}$ (for $\mathrm{HA}: \mathrm{Col}=1.25: 1$ ). The characteristic peak for $\mathrm{GO}$ at $2 \theta=11^{\circ}$ was only reported in $\mathrm{Col} / \mathrm{GO} / \mathrm{HA}(\mathrm{HA}: \mathrm{Col}=1.25: 1)$ while the characteristic peak for $\mathrm{Col}$ at $2 \theta=21^{\circ}$ was only visible in $\mathrm{Col} / \mathrm{GO} / \mathrm{HA}$. 


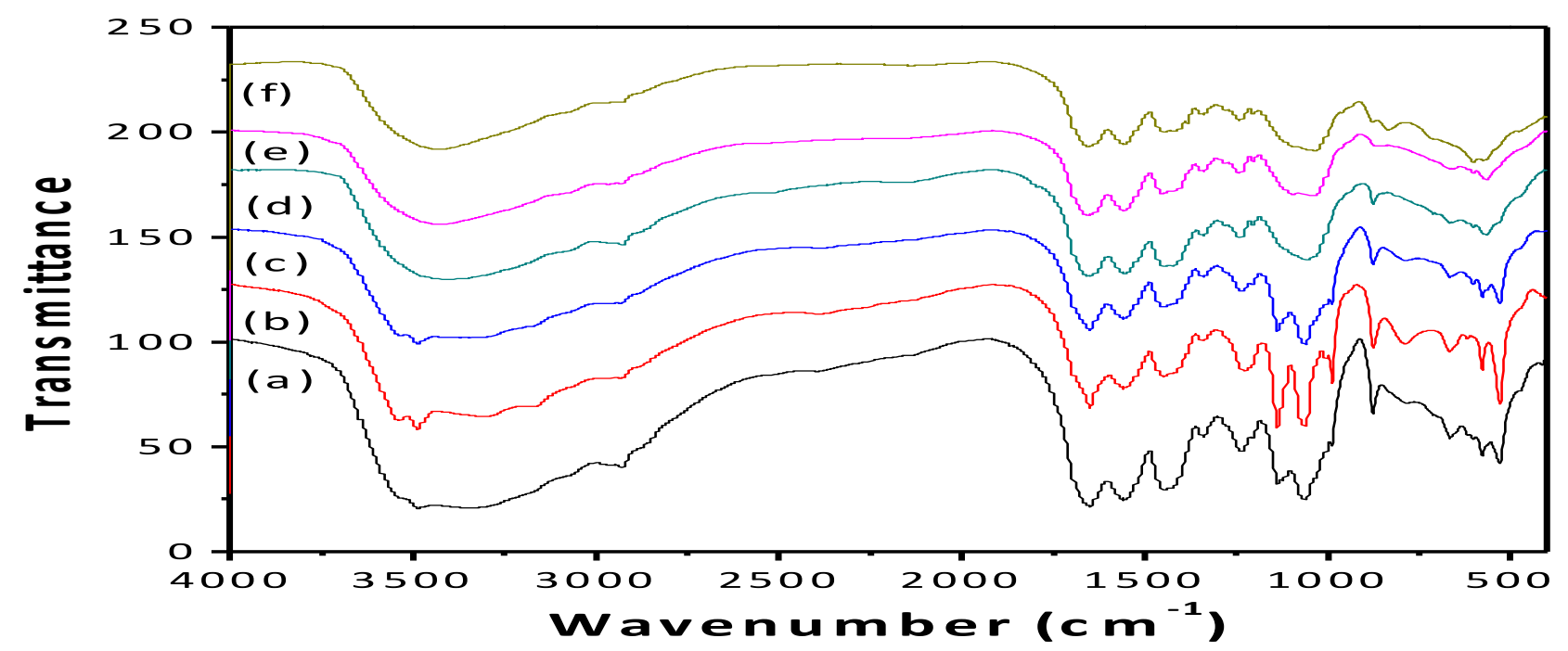

Figure 3. FTIR spectra of as-prepared porous scaffolds. (a) $\mathrm{Col} / \mathrm{GO} / \mathrm{HA}(\mathrm{HA}: \mathrm{Col}=0.25: 1)$; (b) $\mathrm{Col} / \mathrm{GO} / \mathrm{HA}(\mathrm{HA}: \mathrm{Col}$ $=0.5: 1) ;(\mathrm{c}) \mathrm{Col} / \mathrm{GO} / \mathrm{HA}(\mathrm{HA}: \mathrm{Col}=1: 1) ;(\mathrm{d}) \mathrm{Col} / \mathrm{GO} / \mathrm{HA}(\mathrm{HA}: \mathrm{Col}=1.25: 1) ;(\mathrm{e}) \mathrm{Col} / \mathrm{GO}$; and (f) pure Col

Figure 3 above shows the FTIR spectra of pure $\mathrm{Col}, \mathrm{Col} / \mathrm{GO}$, and $\mathrm{Col} / \mathrm{GO} / \mathrm{HA}$ composite scaffolds, revealing the absorption peaks that are characteristic to the different components that make up the scaffolds. A wide and strong absorption peak near $3430 \mathrm{~cm}-1$ is visible in all the scaffold samples. A number of peaks were also seen between $500 \mathrm{~cm}-1$ to $750 \mathrm{~cm}-1$ wavelength.

\section{Mechanical properties of as-prepared $\mathrm{Col} / \mathrm{GO} / \mathrm{HA}$ nanocomposite scaffolds}

The ability of the scaffold materials to resist compression was measured using INSTRON-5967 and the results are shown in Table 1. The results show that compressive stress at maximum load is almost directly proportional to the concentration of $\mathrm{HA}$. It is worth noting that the compressive stress in $\mathrm{Col} / \mathrm{GO} / \mathrm{HA}(\mathrm{HA}: \mathrm{Col}=1: 1)$ was lower than that of $\mathrm{Col} / \mathrm{GO} / \mathrm{HA}(\mathrm{HA}: \mathrm{Col}=0.5: 1)$. Pure Col scaffolds had the least compressive stress of all at maximum load.

Table 1. Compressive stress of as-prepared porous scaffolds.

\begin{tabular}{llll}
\hline Samples & Height of pressure plate $[\mathrm{mm}]$ & $\begin{array}{l}\text { Maximum load } \\
{[\mathrm{N}]}\end{array}$ & $\begin{array}{l}\text { Compressive stress at maximum load [MPa] } \\
\mathrm{Col} / \mathrm{GO} / \mathrm{HA}^{\mathrm{a}}\end{array} \mathrm{H}^{\mathrm{b}}$ \\
$\mathrm{Col} / \mathrm{GO} / \mathrm{HA}^{\mathrm{c}}$ & 10.00000 & 3.49194 & 0.04446 \\
$\mathrm{Col} / \mathrm{GO} / \mathrm{HA}^{\mathrm{c}}$ & 10.00000 & 4.83388 & 0.06155 \\
$\mathrm{Col} / \mathrm{GO} / \mathrm{HA}^{\mathrm{d}}$ & 10.00000 & 4.41889 & 0.05626 \\
$\mathrm{Col} / \mathrm{GO}$ & 10.00000 & 6.12309 & 0.07796 \\
$\mathrm{Pure} \mathrm{Col}$ & 10.00000 & 4.37390 & 0.05569 \\
Average value & $\mathbf{1 0 . 0 0 0 0 0}$ & 1.27305 & 0.01621 \\
Standard variance & $\mathbf{0 . 0 0 0 0 0}$ & $\mathbf{4 . 0 8 5 7 9}$ & $\mathbf{0 . 0 5 2 0 2}$ \\
\hline
\end{tabular}

Note: a: $(\mathrm{HA}: \mathrm{Col}=0.25: 1) ; \mathrm{b}:(\mathrm{HA}: \mathrm{Col}=0.5: 1) ; \mathrm{c}:(\mathrm{HA}: \mathrm{Col}=1: 1) ; \mathrm{d}:(\mathrm{HA}: \mathrm{Col}=1.25: 1)$. 


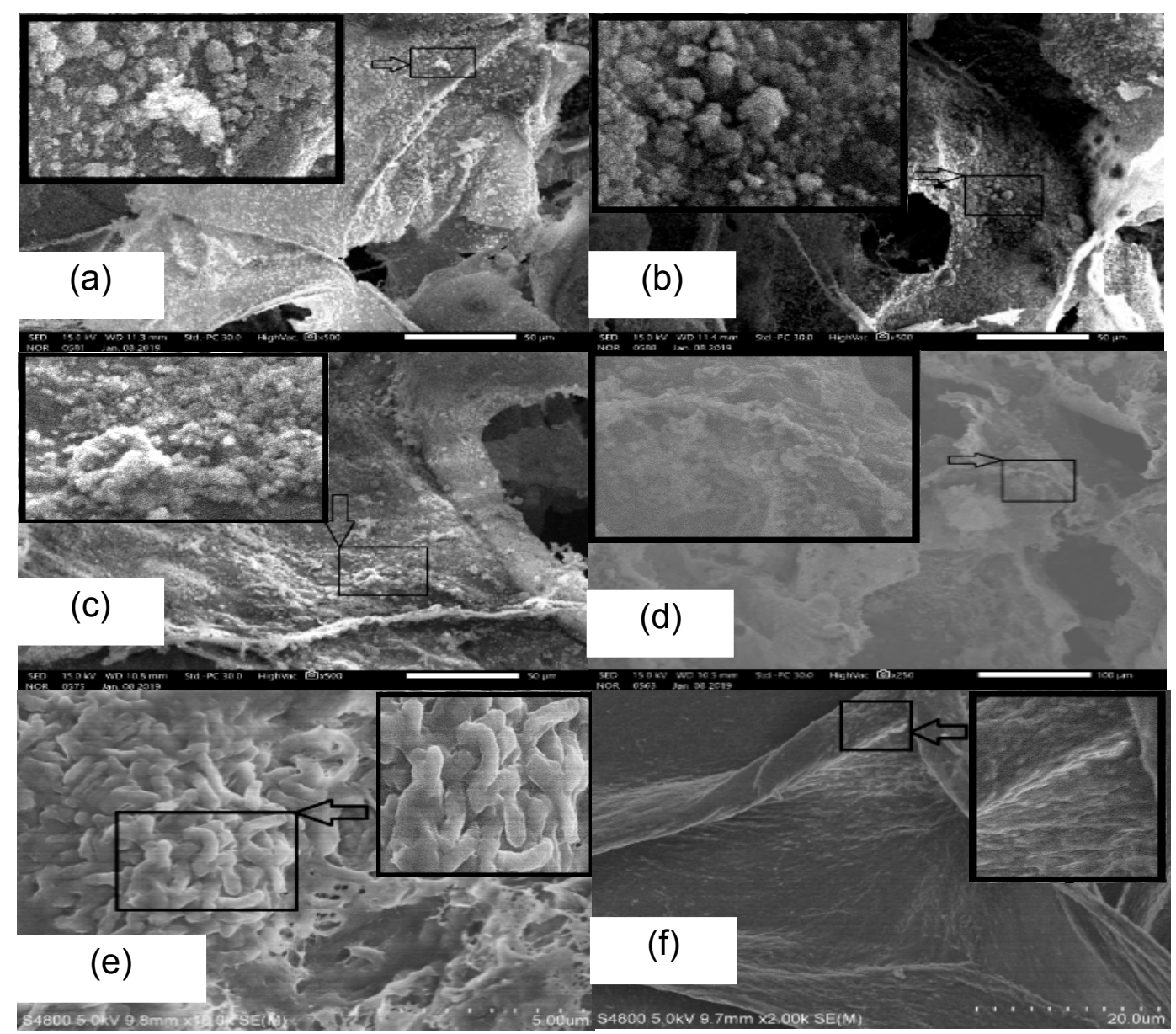

Figure 4. SEM images of rBMSCs cultured on as-prepared scaffolds. (a) Col/GO/HA $(\mathrm{HA}: \mathrm{Col}=0.25: 1)$; (b) $\mathrm{Col} / \mathrm{GO} / \mathrm{HA}(\mathrm{HA}: \mathrm{Col}=0.5: 1) ;(\mathrm{c}) \mathrm{Col} / \mathrm{GO} / \mathrm{HA}(\mathrm{HA}: \mathrm{Col}=1: 1)$; (d) $\mathrm{Col} / \mathrm{GO} / \mathrm{HA}(\mathrm{HA}: \mathrm{Col}=1.25: 1)$; (e) $\mathrm{Col} / \mathrm{GO}$; and

(f) pure Col. The magnified areas in the images show the rBMSCs and their morphology on the scaffolds.

\section{Cell culture}

After Day 7 of culturing rBMSCs on the Col/GO composite scaffolds using growth media, the cells were dedydrated, fixed and freeze-dried while on the scaffolds before taking the scaffolds for imaging. Figure 4 above shows the SEM images of the as-prepared scaffolds with rBMSCs cultured on them. The magnified areas in the SEM images show the rBMSCs and their morphology on the scaffolds. The rBMSCs can be seen covering almost the entire surface of the composite scaffolds. 


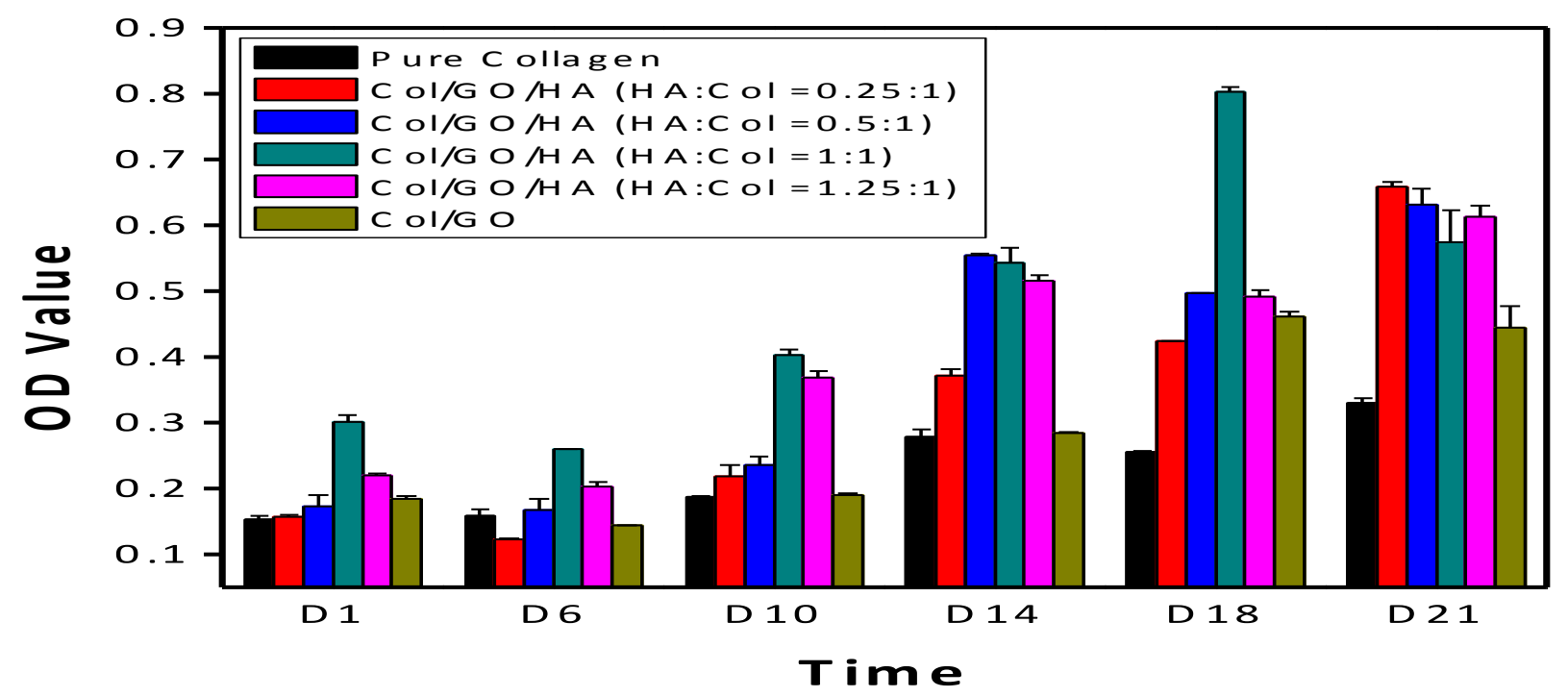

Figure 5. MTT assay for cell viabilities of rBMSCs cultured on as-prepared porous scaffolds. When compared with pure Col scaffold, a considerable increase on cell viability was observed. The cell viability cultured on $\mathrm{Col} / \mathrm{GO} / \mathrm{HA}(1: 1)$ displayed the highest OD value among the tested groups.

Figure 5 above shows the cell viabilities for $\mathrm{rBMSCs}$ on $\mathrm{Col} / \mathrm{GO} / \mathrm{HA}, \mathrm{Col} / \mathrm{Go}$ and pure Col scaffolds. The bar graphs show that the rBMSCs remained viable on the scaffolds up to Day 21. On average, the results show that the proliferation of the rBMSCs increased as the days went by. The viability only decreased slightly in all the composite scaffolds between Day 1 and Day 6 . The viability was measured using the optic density (OD) readings from the graphs. The lowest OD was recorded in $\mathrm{Col} / \mathrm{GO} / \mathrm{HA}(0.25: 1)$ composite scaffolds on Day 6 and the highest was recorded in $\mathrm{Col} / \mathrm{GO} / \mathrm{HA}$ (1:1) composite scaffolds on Day 18.

The osteogenic differentiation ability of the rBMSCs was analysed using the Alizarin Red staining test. Figure 6 below shows the Alizarin red staining results for the cells that were harvested from the scaffolds on which they were cultured. Osteogenesis was revealed in the rBMSCs which were differentiated for 14 days using the osteogenic differentiation media. Alizarin red was used to stain for traces of calcium deposits in the samples and the orange-red stains in the samples reveal a positive test for calcium deposits. The arrows in the images show the orange-red stained calcium deposits that indicate the osteogenic capability of the rBMSCs to form bone tissue. 


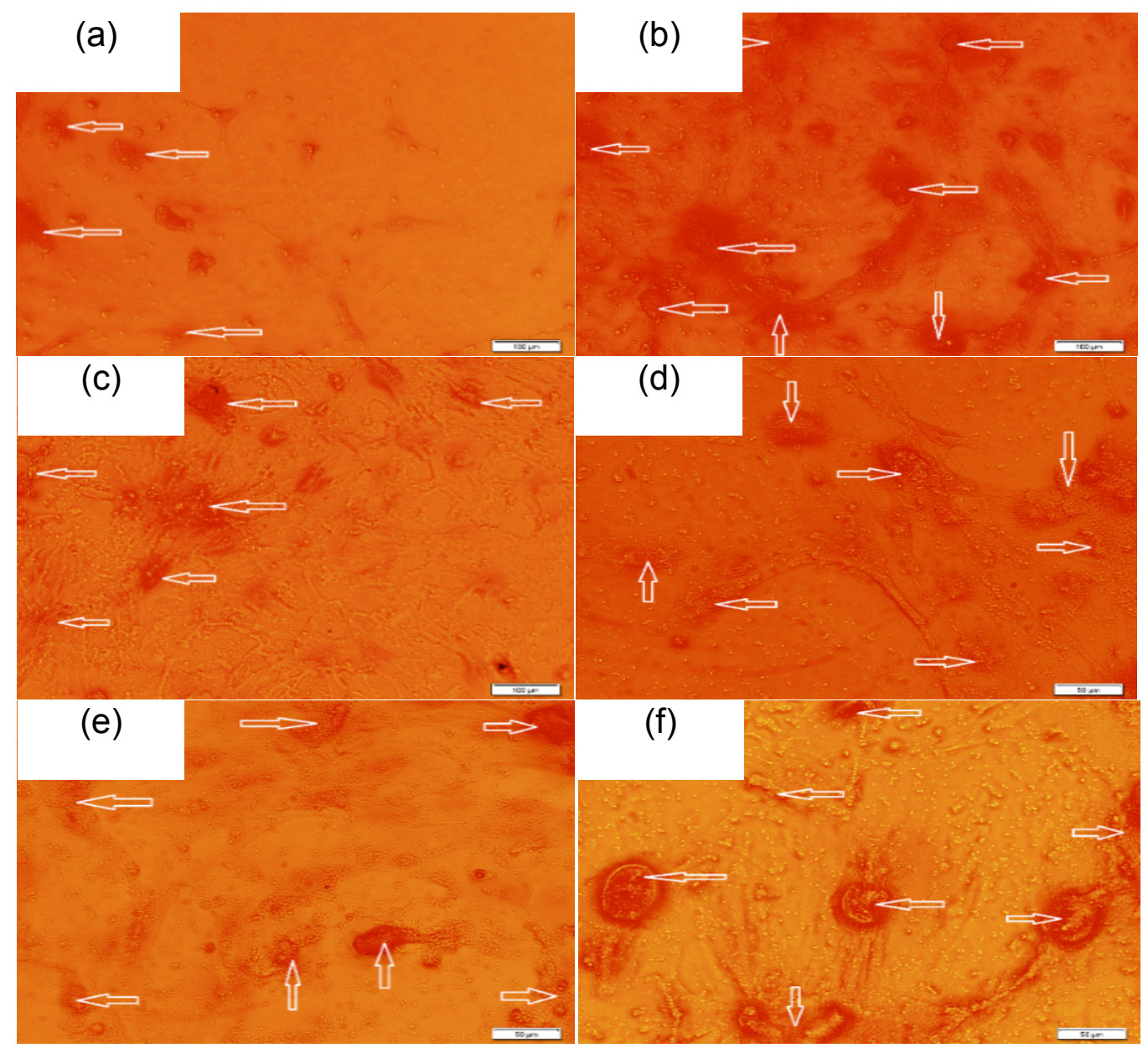

Figure 6. Images of rBMSCs stained using Alizarin red after the cells were cultured for 14 days on as-prepared porous scaffolds. (a) $\mathrm{Col} / \mathrm{GO} / \mathrm{HA}(\mathrm{HA}: \mathrm{Col}=0.25: 1$ ); (b) $\mathrm{Col} / \mathrm{GO} / \mathrm{HA}$ $(\mathrm{HA}: \mathrm{Col}=0.5: 1) ;(\mathrm{c}) \mathrm{Col} / \mathrm{GO} / \mathrm{HA}(\mathrm{HA}: \mathrm{Col}=1: 1) ;(\mathrm{d}) \mathrm{Col} / \mathrm{GO} / \mathrm{HA}(\mathrm{HA}: \mathrm{Col}=1.25: 1) ;(\mathrm{e})$ $\mathrm{Col} / \mathrm{GO}$; and (f) pure Col. The arrows show the calcium deposits that indicate the osteogenic capability of the rBMSCs to form bone tissue.

\section{Discussion}

\section{Structural analysis of the scaffolds}

As shown in Figure 1, Col/GO/HA, Col/GO and pure Col scaffolds all exhibited an isotropic structure following freezing and lyophilisation. The application of the scaffolds and the type of cells used determine the optimal pore size for the scaffolds and according to Gibson et al. [18], the optimal size of the pores range from 20-500 $\mathrm{\mu m}$. A larger pore size has been reported to be associated with higher final freezing temperatures in which there is a slower rate at which heat is extracted from the scaffolds thereby requiring an extended freezing time [19]. As it can also be observed from Figure 1, the number of pores with a diameter larger than $100 \mu \mathrm{m}$ decreased as the concentration of HA increased in the samples and this can be attributed to the increased total concentration of the materials in $\mathrm{Col} / \mathrm{GO} / \mathrm{HA}$ scaffolds as compared to pure Col scaffolds. These results are consistent with the ones reported by Xia et al. [20] in 
which an increase in the apatite content in the collagen-based scaffolds from 0-54 wt.\% resulted into a decrease in the number of pores with a diameter of more than $100 \mu \mathrm{m}$.

It has been reported that scaffolds with porosity of greater than $90 \%$ are better suited for cell migration, nutrient and waste transportation as well as the vascularization throughout the scaffolds [21]. Pure $\mathrm{Col}$ and $\mathrm{Col} / \mathrm{GO} / \mathrm{HA}$ ( $\mathrm{HA}: \mathrm{Col}=0.25: 1)$ scaffolds exhibited the highest porosity $(99.9 \%)$ and also largest diameter of the pore sizes as compared to the rest of the scaffolds. As expected, the lowest porosity $(98.3 \%)$ was recorded in $\mathrm{Col} / \mathrm{GO} / \mathrm{HA} \quad(\mathrm{HA}: \mathrm{Col}=1.25: 1$ ) considering that studies have already reported that the addition of HA to Colbased scaffolds and increasing the total concentration of the materials used reduces the porosity of the scaffolds. Col/GO scaffolds had a porosity of $99.4 \%$ but the diameter of the pores was noticeably much smaller than that of pure Col scaffolds. On the contrary, Norahan et al. [22] found that the addition of GO had no bearing on the pore size and porosity of Col scaffolds. This difference may be due to the variations in the addition methods of GO in these two studies.

The incorporation of HA and GO into the scaffolds was analysed using XRD. From the XRD patterns in Figure 2, it can be seen that the each of the $\mathrm{Col} / \mathrm{GO} / \mathrm{HA}$ composite scaffolds showed at least one of the characteristic peaks for $\mathrm{HA}$ that appeared at $2 \vartheta=25.8^{\circ}, 31.7^{\circ}, 32.2^{\circ}$, or $32.8^{\circ}$. This is in line with what other studies have demonstrated that HA has typical $2 \vartheta$ indices at $25.8^{\circ}$, $31.7^{\circ}, 32.2^{\circ}, 32.8^{\circ}$, and $40^{\circ}$ [23]. This, therefore, indicates that HA was duly incorporated in the Col scaffolds. The characteristic peaks that appear broader due to the presence of $\mathrm{HA}$ in the samples indicate a low crystallinity and this suggests a similarity with the minerals present in natural bones [24]. Only $\mathrm{Col} / \mathrm{GO} / \mathrm{HA}$ (HA:Col =1.25:1) composite scaffolds showed the characteristic peak for $\mathrm{GO}$ at $2 \vartheta=11^{\circ}$ and also only the $\mathrm{Col} / \mathrm{GO} / \mathrm{HA}$ composite scaffolds ( samples a, b, c \& d) showed the characteristic peaks for Col at $2 \vartheta=21^{\circ}$. The homogenous distribution of GO in the collagen solution and the formation of fully exfoliated structures may be associated with the nonappearance of regular characteristic peaks for GO [25].

A wide and strong absorption peak that corresponds to the vibrational peak of -OH group can be seen near $3430 \mathrm{~cm}-1$ in all the samples. The -OH functional group can either be from the HA crystals or from the water that was absorbed by the composite scaffolds. For all the $\mathrm{Col} / \mathrm{GO} / \mathrm{HA}$ scaffolds, except sample d (HA:Col =1.25:1), the peaks near $988 \mathrm{~cm}-1,1063 \mathrm{~cm}-1$ and $1136 \mathrm{~cm}-1$ are indicative of the various vibration modes of the phosphate group that is present in HA. The characteristic peaks that are associated with the carbonate group were also visible in all the scaffolds near $1449 \mathrm{~cm}-1$ (a), $1450 \mathrm{~cm}-1$ (b), $1450 \mathrm{~cm}-1$ (c), $1449 \mathrm{~cm}-1$ (d), $1452 \mathrm{~cm}-1$ (e) and $1451 \mathrm{~cm}-1$ (f). These characteristic peaks for phosphate and carbonate groups are consistent with what was reported previously [26]. Since all the scaffolds contained Col, the typical amide peaks were observed on all the scaffolds with amide I near $1649 \mathrm{~cm}-1$ (a), $1650 \mathrm{~cm}-1$ (b), $1651 \mathrm{~cm}-1$ (c), $1659 \mathrm{~cm}-1$ (d and e) and $1655 \mathrm{~cm}-1$ (f), amide II near 1557 cm-1 (a and e), $1561 \mathrm{~cm}-1$ (b, c, and f) and $155 \mathrm{~cm}-1$ (d), amide III near 1237 cm-1 (a), 1229 cm-1 (b), 1235 cm-1 (c), $1240 \mathrm{~cm}-1$ (d, e, and f). Similarly, a different study stated that FTIR spectra of collagen-based scaffolds showed characteristic amide I, II and III peaks at $1645 \mathrm{~cm}-1,1549 \mathrm{~cm}-1$ and $1243 \mathrm{~cm}-1$, respectively [27]. 


\section{Mechanical properties of as-prepared Col/GO/HA nanocomposite scaffolds}

From the results of compressive stress at maximum load in Table 1, it is clear that the addition of $\mathrm{GO}$ and $\mathrm{HA}$ to Col scaffolds greatly enhanced the compressive stress of the scaffolds. The compressive stress was recorded with the highest value at a ratio of $\mathrm{HA}: \mathrm{Col}=1.25: 1 \mathrm{in} \mathrm{Col} / \mathrm{GO} / \mathrm{HA}$ scaffolds. This means that the compressive stress increased by almost $480 \%$ after adding HA to Col scaffolds. The deposits of HA that are tangled between the Col fibres result into increased resistance of the collagenous scaffolds to deformation [28] and also the addition of GO to Col enhances the strength of the scaffolds [22]. The addition of $\mathrm{HA}$ and $\mathrm{GO}$ to $\mathrm{Col}$ enhances the mechanical and degradation properties of the scaffolds since Col on its own lacks such essential properties in bone tissue engineering.

\section{In Vitro Analysis}

From The attachment, proliferation and the morphological changes of the rBMSCs that were cultured on the scaffolds were observed using SEM. Figure 4 shows the SEM images of the cells on the scaffolds. From the images, it is evident that all the scaffolds were able to support cell adhesion and proliferation. In contrast to the SEM images in Figure 1, the images in Figure 4 show rBMSCs covering almost the entire surface of the scaffolds as they had proliferated successfully. Norahan et al. [22] also reported in their study that the cells that were cultured on collagen-based scaffolds had successfully attached and covered the surface of the materials.

The viability of the rBMSCs on the as-prepared scaffolds was assessed using an MTT assay after culturing the cells for 21 days using growth media. It can be seen from the results in Figure 5that the materials are not cytotoxic in nature. This is evident by the continued proliferation of the rBMSCs for the entire duration they were on the scaffolds. At Day 1 of incubation, the cells were viable on all the scaffolds with no much difference amongst the scaffolds except for $\mathrm{Col} / \mathrm{GO} / \mathrm{HA}$ (1:1) which showed a slightly increased cell proliferation than the other scaffolds. There was a reduction in cell proliferation on all the scaffolds at Day 6 except for pure Col which was used as the control. This suggests that the presence of $\mathrm{GO}$ and $\mathrm{HA}$ was responsible for the slight suppression of the proliferation of the rBMSCs that were seeded on the test materials. This claim is supported by several preceding studies which reported that the presence of numerous surface functional groups in GO increases intracellular reactive oxygen species levels which may somehow induce cell apoptosis [29-31]. HA has also been considered to demonstrate some levels of cytotoxicity mainly due to its intrinsic characteristics like alkalinity $[14,32]$.

As it can be seen from Figure 5, the suppression effect of GO and HA on the proliferation of rBMSCs was almost negligible after Day 6. From Day 6 to Day 18, cell viability increased tremendously with an optic density (OD) value of $>0.5$ for $\mathrm{Col} / \mathrm{GO} / \mathrm{HA}(\mathrm{HA}: \mathrm{Col}=0.5: 1)$ and $\mathrm{Col} / \mathrm{GO} / \mathrm{HA}(\mathrm{HA}: \mathrm{Col}=1: 1)$ at Day 14. The $\mathrm{OD}$ value for $\mathrm{Col} / \mathrm{GO} / \mathrm{HA}(\mathrm{HA}: \mathrm{Col}=1.25: 1)$ was also noticeably higher at Day 14 though it was slightly below 0.5 (OD value). The highest OD value 
was recorded at Day 18 where $\mathrm{Col} / \mathrm{GO} / \mathrm{HA}(\mathrm{HA}: \mathrm{Col}=1: 1)$ scaffolds had an OD value of about 0.8 . These results indicate that the addition of GO to Col scaffolds resulted into an increased cell viability at Day 18 and 21. Furthermore, these results show that HA increased the cell viability even more as compared to GO. This is evident in Figure 5 where the scaffolds that contained HA exhibited a higher OD value than the $\mathrm{Col} / \mathrm{GO}$ scaffolds. In fact, the scaffolds with a higher HA concentration exhibited a better cell viability than those with a lower HA concentration. It can therefore be concluded that the increased cell viability in $\mathrm{Col} / \mathrm{GO} / \mathrm{HA}$ (HA: $\mathrm{Col}=1: 1$ ) was as a result of the presence of $\mathrm{HA}$ in the scaffolds rather than GO. Generally, the MTT assay results shows that the cell viability on the as-prepared scaffolds increased as the days went by.

The osteogenic differentiation results in Figure 6 indicate that the cultured rBMSCs that were harvested from the as-prepared composite scaffolds were able to form calcified tissue which was able to be stained orange-red by the alizarin red staining. These results suggest that the rBMSCs that were cultured on pure $\mathrm{Col}, \mathrm{Col} / \mathrm{GO}$ and $\mathrm{Col} / \mathrm{GO} / \mathrm{HA}$ composite scaffolds were able to successfully differentiate into calcified tissue that resembles bone tissue. In a different study, it was reported that the presence of ascorbic acid, dexamethasone and BetaGlycerophosphate as growth factors in the osteogenic differentiation media resulted in the rBMSCs forming calcified tissue which is an indication for osteogenesis [15]. There wasn't much difference in the calcification of the cultures in pure $\mathrm{Col}$ and $\mathrm{Col} / \mathrm{GO}$ scaffolds which may be attributed to the very low concentration of GO that was added to the samples. On the other hand, the addition of $\mathrm{HA}$ resulted into an increased levels of calcification with $\mathrm{Col} / \mathrm{GO} / \mathrm{HA}$ ( $\mathrm{HA}: \mathrm{Col}=0.5: 1)$ showing the highest levels of calcification. Other studies have reported that GO and HA synergistically increases calcium deposition in stem cells thereby accelerating the osteogenesis of these cells [14, 16, 33].

\section{Conclusions}

In summary, a series of $3 \mathrm{D}$ porous $\mathrm{Col} / \mathrm{GO} / \mathrm{HA}$ nanocomposite scaffolds were successfully prepared using the freeze-drying technique. The incorporation of GO and HA greatly improved the mechanical as well as the functional properties of the Col-based scaffolds. The rBMSCs were able to successfully attach and proliferate on the as-prepared scaffolds which demonstrates the biocompatibility of the scaffolds. Cell viability was found to be higher on scaffolds with a higher concentration of HA than on the other scaffolds with a lower HA concentration or even without HA at all. In vitro experiments also indicated the presence of calcium deposits after the cells were seeded on the scaffolds and cultured for 14 days using the osteogenic differentiation medium. Out of all the scaffold samples, this study demonstrated that $\mathrm{Col} / \mathrm{GO} / \mathrm{HA} \quad(\mathrm{HA}: \mathrm{Col}=0.5: 1)$ porous composite scaffolds exhibited better structural as well as functional characteristics to be used in bone tissue engineering applications. This, therefore, points to the need for further studies on the hemocompatibilities of these scaffolds as well as conducting animal experiments to establish the extent to which $\mathrm{Col} / \mathrm{GO} / \mathrm{HA}$ (HA: $\mathrm{Col}=0.5: 1)$ porous composite scaffolds would be able to restore damaged bone tissue. 


\section{Abbreviations}

AA: acetic acid; CaP: calcium phosphate; Col: collagen; DMEM: Dulbecco's Modified Eagle's Medium; DMSO: dimethyl sulfoxide; FBS: foetal bovine serum; FT-IR: Fourier Transform Infra-Red; GO: graphene oxide; HA: hydroxyapatite; hMSCs: the human mesenchymal stem cells; MTT: 3-(4, 5-dimethyl-2-thiazolyl)2,5-diphenyl-2-H-tetrazolium bromide; OD: optic density; rBMSCs: rat bone marrow mesenchymal stem cells; SEM: scanning electron microscopy; XRD: Xray diffraction.

\section{References:}

1. Chen F., L.X., Advancing biomaterials of human origin for tissue engineering. Prog Polym Sci, 2016. 53: p. 86-168.

2. F.J., O.B., Biomaterials \& scaffolds for tissue engineering. Materialstoday, 2011. 14(3): p. 88-95.

3. Sultana N., L.M.M., Composite Synthetic Scaffolds for Tissue Engineering and Regenerative Medicine. Springer Briefs in Materials, 2015.

4. Gopal S.K., U.K.S., Sowndarya S., Suresh, P.B., Rose, C., Isolation, characterization, and in vitro evaluation of bovine rumen submucosa films of collagen or chitosan-treated collagen. J Biomater Appl., 2016. 30(6): p. 780-792.

5. P., K., Laser flash synthesis of graphene and its inorganic analogues: an innovative breakthrough with immense promise. RSC Adv., 2013. 3: p. 11987-12002.

6. Nishida E., M.H., Kato A., et al., Graphene oxide scaffold accelerates cellular proliferative response and alveolar bone healing of tooth extraction socket. Int. J. Nanomed., 2016. 11: p. $2265-2277$.

7. Girão A.F., G.G., Bhangra K.S., et al., Electrostatic self-assembled graphene oxide-collagen scaffolds towards a three-dimensional microenvironment for biomimetic applications. RSC Adv., 2016. 6: p. 49039-49051.

8. Wang A., P.K., Dong B., et al. , Role of surface charge and oxidative stress in cytotoxicity and genotoxicity of graphene oxide towards human lung fibroblast cells. J Appl Toxicol., 2013. 33(10): p. 1156-1164.

9. Zhong, Y., \& Ji, B., Impact of cell shape on cell migration behavior on elastic substrate. Biofabrication, 2013. 5.

10. Thein-Han, W.W., \& Xu, H.H.K., Collagen-Calcium Phosphate Cement Scaffolds Seeded with Umbilical Cord Stem Cells for Bone Tissue Engineering. TISSUE ENGINEERING, 2011. 17.

11. Al-Munajjed, A.A., \& O'Brien, F.J., Influence of a novel calcium-phosphate coating on the mechanical properties of highly porous collagen scaffolds for bone repair. Journal of the Mechanical Behavior of Biomedical Materials, 2009. 2: p. 138-146.

12. Chen D., Z.X., Chen S., et. al., One-pot fabrication of FePt/reduced graphene oxide composites as highly active and stable electrocatalysts for the oxygen reduction reaction. Carbon, 2014. 68: p. $755-762$.

13. Huang W., M.Z., Chen L., et. al., Synthesis and characterisation of fluorescent and biocompatible hydroxyapatite nanoparticles with cerium doping. Micro \& Nano Letters, 2018. 13(5): p. 699-703.

14. Lee J.H., S.Y.C., Lee S., et. al., Enhanced Osteogenesis by Reduced Graphene Oxide/Hydroxyapatite Nanocomposites. Scientific Reports 2015. 5.

15. Smajilagić A., A.M., Redžić A., et. al. , Rat bone marrow stem cells isolation and culture as a bone formative experimental system. Bosn J Basic Med Sci 2013. 13(1): p. 27-30.

16. Lee J.H., S.Y.C., Jin O.S., et. al. , Reduced graphene oxide-coated hydroxyapatite composites stimulate spontaneous osteogenic differentiation of human mesenchymal stem cells. Nanoscale, 2015. 7(1-9).

17. Jia L., D.Z., Fan D., et. al. , Human-like collagen/nano-hydroxyapatite scaffolds for the culture of chondrocytes. Mater Sci Eng C, 2013. 33: p. 727-734.

18. Gibson, L.J., Ashby, M., \& Harley, B.A., Cellular Materials in Nature and Medicine. . 2010, Cambridge, UK: Cambridge University Press. 
19. Haugh M.G., M.C.M., O'Brien F.J., Novel freeze-drying methods to produce a range of collagenglycosaminoglycan scaffolds with tailored mean pore sizes. Tissue Eng C 2010. 16: p. 887894.

20. Xia Z., Y.X., Jiang X., et al. , Fabrication and characterization of biomimetic collagen-apatite scaffolds with tunable structures for bone tissue engineering. Acta Biomater., 2013.

21. Venugopal J.R., P.M.P., Mukherjee S., et. al., Biomaterial strategies for alleviation of myocardial infarction. J Royal Soc Interface 2012. 9: p. 1-19.

22. Norahan M.H., A.M., Ghahremanzadeh R., et. al., Electroactive graphene oxide-incorporated collagen assisting vascularization for cardiac tissue engineering. J Biomed Mater Res., 2018: p. $1-16$.

23. Brundavanam R.K, P.G.E.J., Fawcett D., Modelling the Crystal Structure of a $30 \mathrm{~nm}$ Sized Particle based Hydroxyapatite Powder Synthesised under the Influence of Ultrasound Irradiation from X-ray powder Diffraction Data. American Journal of Materials Science 2013. 3(4): p. 84-90.

24. Guan, J., Yang, J., Dai, J., Qin, Y., Wang, Y., Guo, Y., Ke, Q., \& Zhang, C. , Bioinspired nanostructured hydroxyapatite/collagen three-dimensional porous scaffolds for bone tissue engineering. RSC Advances, 2015. 5(46): p. 36175-36184.

25. Chaudhuri B., B.D., Moroni L., Pramanik K., Myoblast differentiation of human mesenchymal stem cells on graphene oxide and electrospun graphene oxide-polymer composite fibrous meshes: Importance of graphene oxide conductivity and dielectric constant on their biocompatibility. Biofabrication, 2015. 7.

26. Yoruc A.B.H., A.A.K., Synthesis of Hydroxyapatite/Collagen (HA/COL) Composite Powder Using a Novel Precipitation Technique. ACTA PHYSICA POLONICA A., 2015. 127(4): p. 1264-1267.

27. Deepachitra R., R.V.S.T., Graphene oxide incorporated collagen-fibrin biofilm as a wound dressing material. RSC Adv., 2014. 4: p. 62717-62727.

28. Wahl D.A., C.J.T., Collagen-hydroxyapatite composites for hard tissue repair. European Cells and Materials 2006. 11: p. 43-56.

29. Chong Y., M.Y., Shen H., et. al. , The in vitro and in vivo toxicity of graphene quantum dots. Biomaterials, 2014. 35.

30. Park E. J., L.G.H., Han B. S., et. al., Toxic response of graphene nanoplatelets in vivo and in vitro. Arch. Toxicol., 2015. 89.

31. Li D., N.W., Chen L., et. al. , Self-Assembled Hydroxyapatite-Graphene Scaffold for Photothermal Cancer Therapy and Bone Regeneration. J. Biomed. Nanotechnol., 2018. 14: p. 2003-2017.

32. Wang L., Z.G., Liu H., et. al. , Nano-hydroxyapatite particles induce apoptosis on MC3T3-E1 cells and tissue cells in SD rats. Nanoscale, 2012. 4: p. 2894-2899

33. Tatavarty R., D.H., Lu G., Taylor R. J. \& Bi X., Synergistic acceleration in the osteogenesis of human mesenchymal stem cells by graphene oxide-calcium phosphate nanocomposites. Chem. Commun., 2014. 50(62): p. 8484-8487. 